Southern Methodist University

SMU Scholar

Temerlin Advertising Institute Research

Temerlin Advertising Institute

Spring 2000

\title{
Cross Media Promotion of the Internet in Television Commercials
}

Steven M. Edwards

Southern Methodist University, steve@smu.edu

Carrie La Ferle

Southern Methodist University, laferle@smu.edu

Follow this and additional works at: https://scholar.smu.edu/arts_temerlin_research

Part of the Advertising and Promotion Management Commons, Arts and Humanities Commons, and the Computer Sciences Commons

\section{Recommended Citation}

Edwards, Steven M. and La Ferle, Carrie, "Cross Media Promotion of the Internet in Television Commercials" (2000). Temerlin Advertising Institute Research. 2.

https://scholar.smu.edu/arts_temerlin_research/2

This document is brought to you for free and open access by the Temerlin Advertising Institute at SMU Scholar. It has been accepted for inclusion in Temerlin Advertising Institute Research by an authorized administrator of SMU Scholar. For more information, please visit http://digitalrepository.smu.edu. 


\title{
Cross Media Promotion of the Internet in Television Commercials
}

\author{
Steven Edwards and Carrie La Ferle
}

Increasing presence of internet addresses across traditional media spurred the current study. Specifically, the study examined the cross media promotion of web site addresses in television commercials to determine if and when they were being used, and by whom? For comparison purposes, other forms of direct response channels were also measured. A clearer understanding of the practice of promoting web sites in television commercials was garnered by examining web site addresses for their size, length, positioning, frequency, product category representation, and other important attributes. The findings provide an initial base from which future growth and style of web site advertising in traditional media can be measured. Results indicate that advertisers may be returning to a bullet theory mentality, believing that if consumers are hit with a web address, they will visit the site. In this study, internet addresses analyzed were usually quite small, flashed quickly, and lacked any kind of support as to why consumers should want to visit a company's Ointernet site. Implications for advertisers and suggestions for future cross media promotion of internet sites are provided.

\section{Introduction}

Today, advertisers recognize the importance of understanding consumers' needs, motivations, and involvement levels as moderators of an ad's effectiveness, however these issues may be secondary in the promotion of web sites in mass media advertising. Given the sophistication of today's advertisers, it is puzzling why advertisements that presumably wish to drive consumers to web sites are not providing them with reasons to visit. Advertisers are simply presenting web addresses and assuming consumers will come. Research is needed focusing on both cross media promotional methods of encouraging consumers to visit web sites, and understanding the reasons that prompt consumers to take action when faced with a direct response advertisement.

This manuscript seeks to explore cross media promotions of immediate Direct Response Channels (DRC) in television commercials. Direct response chan-

Steven Edwards (Ph.D., University of Texas at Austin) is Assistant Professor, Department of Advertising, Michigan State University.

Carrie LaFerle (Ph.D., University of Texas at Austin) is Assistant Professor, Department of Advertising, Michigan State University.

The authors are listed alphabetically. Both authors contributed equally to the article.

The authors wish to thank two anonymous reviewers for their helpful comments on an earlier draft. nels are defined here as methods of contacting a company regarding the product or service advertised such as 800 numbers, local phone numbers, mailing addresses, email addresses, and particularly Universal Resource Locators (also known as URLs or web site addresses).

To date, many advertisers have created web sites performing marketing activities, from corporate public relations to elaborate cyber stores that offer products for sale (Hoffman, Novak, and Chatterjee 1995). However, little is known about how to influence consumers, both online and those engaged with other media, to visit any one particular web site. To render a better understanding of what advertisers are currently doing, television advertisements were content analyzed to investigate the cross media promotion of URLs. Specifically, the goal of the study was to determine the proportion of advertisers promoting URLs in television commercials, the industries that are presently promoting web sites, and to describe how and when URLs are appearing in television commercials.

An examination of these issues is beneficial for assessing the effectiveness of current cross promoting advertising practices of URLs. The results further allow for suggestions to be made regarding how advertisers

Journal of Current lssues and Research in Advertising, Volume 22, Number 1 (Spring 2000). 
could be more effective in driving consumers to internet web pages. Toward these goals, a series of research questions are presented along with the literature to illustrate their importance in understanding the cross media promotion of internet sites.

\section{Literature Review}

\section{The Current State of Advertising Related Internet Research}

Over the past few years, the internet has become one of the hottest areas for research in the field of advertising. In a search for internet related literature, 37,188 articles in a single database (ABI Inform) were found, with over 132 entries related to advertising and the internet for the first two months of 1999 alone. For comparison purposes, there were only 8 articles related to internet advertising in all of 1993. In the field of communication and advertising, literature on the internet has generally concerned the commercial viability of the web, and methods to profit from this new medium. However, freedom of speech issues have also taken center stage, as governments around the world have moved to restrict access to certain materials on the internet.

From a brief review of the web advertising literature on commercial viability and profiting related issues, it appears that a majority of the articles can be classified into four categories: 1) Descriptions of users and growth rates, 2) Development of reach and frequency models and measurement systems for audience exposure, 3) Assessments of attitude and behavior formation, and 4) Examination of the effects of the new media on traditional media.

Focusing on the four categories, the first area of research has to do with describing the environment of the internet. Counts of internet users have been growing steadily from 14 million (Hoffman, Kalsbeek \& Novak 1996) to 37 million (Commerce Net 1997) to 67 million (MRI Cyber Stats 1999). However, advertising practitioners and academicians debate about the internet as the medium of the future (Cook 1994; Dreze and Zufryden 1998; Griffin, Whitehead and Gatlin 1998; Hoffman et al. 1995; McKenna 1995), yet multiple measurements of internet growth indicate phenomenal increases using such indices as domain names (estats 1999), host numbers (Hoffman et al. 1995), or web revenue (Internet Advertising Bureau 1999; Jupiter Communications 1999). Regardless of the hype surrounding the internet most agree that the medium is rapidly changing and information considered current last year is ancient by internet standards today.
Secondly, the development of measurement techniques have been widely researched, with several companies taking the lead in producing systems to rate web pages in a way that is similar to Nielson ratings for television (www.webtrack.com). Researchers are developing and have tested new reach and frequency models to estimate media schedules on the internet (Dreze and Zufryden 1998; Leckenby and Hong 1998; Wood 1998). And, many systems such as PointCast's pay-per-click are being tested that focus on the pricing structure for advertising exposures and are providing advertisers with direct responses from consumers (Spooner 1997).

A third area of research assesses the impact of interactivity on learning and exposure (Bezjian-Avery, Calder and Iacobucci 1998; Ghose and Dou 1998; Raman 1996). Several researchers are questioning the standard measures of recognition and recall, in favor of depth of processing measurements and measurements of click-through with an ad. Still, others are studying the effects of mere exposure to interactive ads (Briggs and Hollis 1997), and the effects of internet design and promotional content on web site effectiveness (Dreze and Zufryden 1997).

The fourth category of internet related research and the area that the current study resides examines the effects of new media on traditional forms of media and vice versa. A few studies investigating the effects of the internet on television viewing have already been undertaken, but the results are inconsistent and more research needs to be done. Coffey and Stipp (1997) found an interaction between the internet and television, but dismissed the demise of television as unlikely. In contrast, Wendland (1998) reported the results of a Strategis Group marketing study showing that $64 \%$ of internet users had reduced their time watching television. Similarly, Shaddick (1998) reported a Marketing Week study showing reduced use of television and magazines, but an increase in the total time spent reading.

Another means by which new media is impacting traditional media is through cross-media promotion. Maddox, Mehta and Daubek (1997) specifically looked at the effect of cross promoting web addresses in television commercials and their effects on attitudes toward advertisers and brands. In general, the results indicated that advertisers that present URLs enjoy positive consumer opinions. However, researchers have not specifically explored the frequency of promoting URLs in television commercials, what product categories are using this technique, how URLs are being presented, nor if current presentations of URLs are following standard practices for effectiveness. 
Therefore, our initial research question seeks to understand the proportion of advertisers using URLs to promote their web sites in television commercials. Secondly, it will be ascertained whether this usage varies by product category. With respect to assessing how URLs are being presented and their level of effectiveness, it is helpful to examine related literature on the use of 800 numbers and disclosure statements in television commercials.

\section{Presentation of URLs, 800 Numbers, and Disclosure Statements}

From sheer observation it is clear that mass media advertisements are being used by advertisers to promote web sites. People hear URLs yelled to them from the radio, they glance over them in magazines and newspapers, and if a person is quick he or she can catch them flashed up on the television screen. URLs, like 800 numbers provide consumers with a means to directly contact the company for more information and/or to engage in a purchase. 800 numbers open the lines of communication between consumers and companies, increase sales by saving customers time (Direct Marketing 1987), and allow customers in distant locations to be reached who would not otherwise have access to certain products or services (Sanghavi 1987). However, the potential for what marketers and consumers can gain by accessing web pages far surpasses the benefits of 800 numbers. Yet the benefits are dependent on consumers being aware that a company's web site exists and knowledge of the URL to access the site. Cross media promotion of URLs in television commercials may be very important in achieving this task, especially given that researchers have found consumers to use print or television $32 \%$ of the time to find out about 800 numbers (Anonymous 1995). Therefore, measurement of how URLs are being presented will help in assessing their effectiveness in communicating with consumers. Due to the paucity of research in this area, consulting the literature on disclosure statements can provide guidance.

Although disclosure statements are not channels for direct response communication, the way they are measured and assessments as to their effectiveness can be applied to the measurement and assessment of URLs. According to information summarized by Hoy and Stankey (1993), both message content and structural factors of the disclosure can influence its effectiveness at grabbing attention and communicating with the audience. Under the assumption that URLs in television advertisements have similar goals of attracting attention and effectively communicating the benefits of visiting a web site, our final two research questions are presented in relation to the structural and content dimensions of URLs in advertisements.

Many structural elements have been identified that may all influence the amount of attention a consumer pays to a URL including: when the URL appears in the commercial, where the URL is presented on the screen, and type size. Further, the number of presentations and presentation modality may also effect memory for URLs in advertisements. Therefore, each of these elements will be examined to determine how effectively URLs are being used in television advertisements.

Research has suggested a primacy effect for attention where information provided early in an advertisement is most likely to receive more attention than messages appearing later in a commercial (Unnava, Burnkrant and Erevelles 1994). With this in mind, a second question related to structure investigates at what point during a commercial is the URL most likely to be shown? In a similar vein, research has suggested that elements placed in the middle of the screen will generate more attention than elements in other locations, as will elements that are larger rather than smaller. Research on disclosures for example (Foxman, Muehling and Moore 1988) suggests that URLs may not be effective if the size of the URL is too small to read. In light of these concerns, it is important to determine the placement of URLs in television ads and the size of URLs presented to assess their effectiveness.

Two final structural factors also of interest in the current study include: the number of times the URL is presented in the advertisement, and the modality of reference to the URL and/or web site. Research has suggested that greater attention and better comprehension occur as the number of sensory channels receiving the same message increases (Prabu 1998; Unnava and Burnkrant 1991). URLs presented more than once should be more effective than URLs presented a single time. Similarly, URLs that are presented both visually and verbally should be better remembered than those presented in a single modality. Therefore, examining the number of times URLs are presented and whether these presentations are visual, verbal, or both are important for understanding the effectiveness of current practices in cross promotion of URLs.

The final research question addresses the message content dimension of effective communication outlined earlier. Rather than focusing on structural factors such as size and location of the URL, the content dimension involves looking at what information is actually conveyed about the message, or in this case the URL and web site. Under the assumption that 
advertisers wish to make contact with consumers, the first step is to attract their attention. But then advertisers must give people a reason to seek out their web site. Parallel research on presenting 800 numbers in TV commercials found that although viewers look favorably toward companies that provide this service (Anonymous 1995), they first want to know why they should make the telephone call (Lewis 1989). Following similar logic, the same problem may be encountered for URLs that are flashed on consumers' television screens or squeezed in at the bottom of print ads. If an incentive or benefit of action is not presented, why should consumers be motivated to take the time and energy to visit a web site? James Hillson, Senior VP of Phase One Research agrees that an ad must help the consumer to understand why they should act. Hillson (1995) cautions, "When advertisers expect viewers to do their work for them, by and large, people don't." Therefore, the ability of a URL to encourage consumers to visit a particular web site may be dependent on the types of benefits consumers are shown. Television ads presenting URLs should go beyond merely flashing a URL on the screen to be effective. Therefore, the final research question asks, what reason, if any, is given by advertisers to direct consumers to their web sites? This question is crucial in assessing the effectiveness of URLs and warrants a brief discussion on the importance of understanding consumers' needs for knowledge.

\section{Consumers' Needs For Knowledge}

Consumer researchers have long understood that people have different needs for information, depending on individual specific characteristics (e.g., prior knowledge) and situational specific characteristics (e.g., time) (Girish and Staelin 1983; Stigler 1961; Kiel and Layton 1981; Bloch, Sherrel and Ridgway 1986). Given that the advertiser can not effect situational variables such as time pressures or geographic locations, but simply direct consumers to the location of the goods for sale, advertisers need to focus on methods by which they can provide for consumers' needs to acquire knowledge for the future, or for intrinsic pleasure (Bloch, Sherrel, and Ridgway 1986).

People have varying backgrounds (Cobb and Hoyer 1985), levels of knowledge (Alba and Hutchinson 1988; Brucks 1985), and make use of information differently depending on their involvement with a product, the advertisement, or the medium (Smith 1993). In the past, advertisers wishing to segment by consumers' informational needs, placed messages with varying amounts of information in different media. Highly informational ads have generally been placed in print vehicles where consumers can control the rate at which the information is accessed; whereas ads with less information, requiring less consumer involvement, have generally been placed in radio or television. Instead of segmenting a market based on the media used, the internet allows consumers to create their own segments based on informational need, by providing consumers with varying levels of information in a single medium.

The internet also provides for two way interaction and a higher level of cognitive commitment on the part of the consumer, bonding the consumer and the company, and creating brand loyalty. Consumers who have had their needs fulfilled from a web site visit will go away satisfied, remembering a positive experience. This positive affect may in turn rub off onto the company as a whole, furthering the chance of a future encounter. Beyond being satisfied, there is also a cost benefit rational for consumers to become brand loyal. It takes consumers' time and energy to become known by a company over the internet. Consumers will often fill out information regarding who they are, their preferences, information desired and so on. If customers are satisfied with the service and information they receive, it is not economical for them to try a new supplier and have to repeat the entire process. Everything points to the notion that the internet has many positive qualities for advertisers, marketers, and consumers. However, at this point in time it is unclear whether advertisers are effectively presenting URLs in advertisements.

\section{The Study}

The current paper seeks to understand how advertisers are actively attracting consumers directly to their web sites. Specifically, the study examines advertisers' use of television to promote web site viewing. A web site is defined as the collection of pages that provide consumers with information on a computer. This is in contrast to a web site address or URL which merely informs people how to come in contact with the site, similar to a telephone number. At this point, it is unclear how many television advertisers are using URLs to promote their web sites, and how they engage in this type of advertising. The present study seeks to describe the current level and style of web site promotion during television commercials. Using content analysis, the research questions (restated below) are used to examine the presentation of URLs in television commercials. The results of this study are intended to provide a better understanding of the current practice, insight into its effectiveness, and possible suggestions for improvement. 
Q1: a) What is the proportion of advertisers promoting web sites in their television ads using URLs?

b) Are some product categories promoting web sites more than others through URLs?

Q2: a) At what point during the commercial is the URL shown?

b) Where is the URL shown on the screen and what is its size?

c) What is the frequency of URL presentation in any one commercial?

d) Are consumers directed toward web sites verbally? (i.e. "visit www....")

Q3: What is the reason, if any, given by advertisers to direct consumers to their web sites? (i.e. "For more information about our product/company visit www.....")

\section{Method}

\section{Television Ad Sample}

A content analysis was performed on a random sample of prime time television ads. In 1997, a week of television commercials was recorded between September 8th to 14 th on the three major television networks (ABC, CBS, and NBC) and Fox ${ }^{1}$. The week of September 8-14 was selected as it was a week that did not involve any special events or major holidays that could skew the representativeness of the sample (Taylor and Stern 1997). For example the week was not during sweeps, nor was it close enough to a major holiday such as Christmas where product categories advertised are often skewed toward toys and other gifts (Muehling and Kolbe 1998). Both local and network ads were included in the sample. Ads were counted as prime time if they fell between 7:00 p.m. to 10:00 p.m. Central Standard Time (CST). Recording of the commercials began after the credits of the 6:30 p.m. show CST and continued until the beginning of the 10:00 p.m. news. A total of 84 one hour segments were collected, of which a random sample of 18 hour segments were selected for coding. The segments were randomly selected by systematically choosing one, one hour segment everyday, rotating time and network (including Fox) until approximately $25 \%$ of ads in the sample were represented by each of the networks.

The sample consisted of 464 individual ads from the four networks ABC: $(26 \%), \mathrm{CBS}(22 \%), \mathrm{NBC}(29 \%)$, and Fox $(23 \%)$. The most represented product categories included ads for Automobiles (15\%), Fast Food (10\%), and Retail Stores (8\%). Thirty second spots dominated the sample (73\%), followed by 15 second commercials (22\%). The remainder of the ads were evenly divided between 10,20, and 60 second ads, at $2 \%$ each. Most of the advertisements contained no opportunity for direct response $(74 \%)$, however twenty-one percent contained one response channel and four percent contained two response channels. URLs were the most common opportunity for response (15\%), followed by 800 numbers $(8 \%)$, and local phone numbers $(3 \%)$.

\section{Television Ad Coding}

The commercials were coded for attributes relating to the use of Direct Response Channels (DRC) on screen. DRCs fell into three categories: URLs, 800 numbers, and local phone numbers. There were no mail or email addresses provided in any of the ads. The ads were coded for the presence or absence of a DRC somewhere in the ad, the number of DRCs presented, and if the ad was web focused or the URL was secondary to the main message. Attributes about the DRC itself were also coded, such as: size, location in the ad (beginning, middle, end), location on the screen (top, middle, bottom), and the frequency of presentation. It was noted if the advertisement directed the audience to the web site verbally or not, and for what reason. The product category was recorded, as was the brand name of the product or service. The ads were also coded as to the program name and the type of programming, the day of the week shown, the time slot, the network, and the length of the commercial. Finally, the contact information (e.g., URL) presented in the ads was recorded, see Exhibit 1 for a listing.

\section{Reliability}

Each ad was coded twice, so that intercoder reliability could be assessed. Ads were coded independently by two trained coders, however due to the nature of the attributes coded there was little subjective judgment required. Of 464 ads coded and 5808 individual judgments made, only 36 discrepancies occurred (.6\%). Any discrepancies in the judgments were reconciled by the coders so that $100 \%$ agreement was attained. Duplicate ads were removed from the analysis as to not confound the reporting of the DRCs with regard to frequency of presentation.

\section{Results}

Of the 464 ads in the study, $335(72 \%)$ were unique and $129(28 \%)$ were duplicates of other ads already coded. Of the original number of ads coded, $119(26 \%)$ 
contained opportunities for direct response, however $27(6 \%)$ of the direct response ads were duplicates. All duplicate ads were removed from the sample for further analysis. Of the 92 ads that remained, 14 contained two possible direct response channels. Most common was a URL/ 800 number combination ( $n=13)$, with one ad offering both a URL and local phone number. These ads with two DRCs were added to the sample for further analysis, raising the sample size from 92 to 106. Table 1 presents a comprehensive list of the results for ads that presented any direct response opportunity broken out by direct response channel.

In regards to the first research question (a), the results indicate that $20.6 \%(n=69)$ of all unique ads coded included web site addresses. This is in comparison to $8 \%$ for ads with 800 numbers and $3 \%$ for ads showing local phone numbers.

As for product categories containing web addresses (b), the findings reveal that ads for Automobiles presented the most URLs (19.6\%), followed by Medicine ads (10.7\%), and ads for Movies (8.9\%). With respect to 800 numbers, the top three categories were: Telephone Services (31.7\%), Automobiles (14.6\%), and Insurance, Credit Cards, and Banking (7.3\%). Finally, at the top of local telephone services was Insurance, Credit Cards, and Banking (33.3\%), followed by Automobiles (22.2\%).

To examine the first part of the second research question (2a), the time at which web addresses were shown was examined. The most common time in an ad for a web address to be presented was at the end (95.7\%), followed by the beginning ( $2.9 \%)$, and then the middle $(1.4 \%)$. Overall, the other direct response channels followed a similar pattern.

The location of the web address on the screen (question $2 \mathrm{~b}$ ), was most commonly at the bottom of the screen in the center $(56.5 \%)$, followed by the bottom right (17.4\%), and bottom left (10.1\%). These results differed slightly from the placement of either 800 or local numbers, where the second most common placement was the center of the screen. For a visual breakdown of DRC placements overall, please see Exhibit 2.

Size was measured as a percentage of the television screen on which the DRC message was shown. The messages were physically measured based on a percentage of the screen height (16.5 inches) of a 25 inch television set and then coded as less than $2 \%, 2 \%$ to $5 \%, 5.1 \%$ to $10 \%$, and $10.1 \%$ to $20 \%$. A video recorder allowed for the tapped commercials to be paused or replayed to verify size. Most URLs were between 2 and $5 \%(50.7 \%)$ of the screen, followed by those that were less than $2 \%(30.4 \%)$, then $5.1 \%$ to $10 \%(15.9 \%)$, and then $10.1 \%$ to. $20 \%(2.9 \%)$. It is interesting to note that for the other direct response channels, very few were less than $2 \%$ of the screen as compared with the web addresses. Please see Exhibit 3 for examples of the various message sizes.

Finally with respect to frequency (question 2c), most web addresses were presented only once in an ad $(98.6 \%)$, and a similar pattern was seen in direct response channels overall (92.5\%). However some ads did present the DRC twice (1.9\%), three times (4.7\%), or even constantly throughout the ad $(.9 \%)$.

Of the $\mathbf{1 0 6}$ ads that contained an opportunity to respond directly, $18.9 \%$ made a verbal reference to the direct response channel (question 2d). Regarding web sites, only $10.1 \%$ were referenced verbally. With respect to the final research question, most ads gave no reason why consumers should visit the web site (91.3\%). However several ads prompted consumers to seek more information $(5.8 \%)$, or order the product (2.9\%). The other direct response channel ads used verbal references more frequently, with 800 numbers at $29.6 \%$ and local numbers at $50 \%$.

It is interesting to point out that an actual web site was presented in only a single ad. This occurred when a news station demonstrated the community information that was available on its site. The ad even illustrated the process by which one could type in a URL on a browser and down load the web site. However, this ad was the one and only exception.

\section{Discussion}

The internet is a new and exciting medium for consumers and advertisers alike. It has the unique ability of combining the features of several media and the added bonus of providing two-way communication with customers and potential customers. Given these unique features, the internet is and will become an important means to build relationships with consumers. However, it must be remembered that consumer interest and use of other media will not just disappear (Buck 1993). Therefore, it is crucial to understand effective methods for the cross media promotion of URLs in order to create awareness and drive consumers to web sites from different media. Companies of tomorrow will be those that create lasting relationships with their consumers, effectively reaching them with personally relevant information, and providing cohesive messages presented across various media (Peppers and Rogers 1993, 1997).

This research explored the use of cross media promotion of URLs in television ads with the assumption that advertisers are seeking greater contact with con- 


\section{Exhibit 1}

\section{List of Web Sites Referenced in Ads}

\section{Transportation}

1. http://www.ford.com

2. http://www.midas.com

3. http://www.toyota.com

4. http://www.oldsmobile.com

5. http://www.suburu.com

6. http://www.pontiac.com

7. http://www.plymouth.com

8. http://www.buick.com

\section{Media}

9. http://www.inandout.com

10. http://www.fox7.com

11. http://www.wishmaster.com

12. http://www.caspervideo.com

13. http://www.kxan.com

14. http:// kissthegirls.com

15. http://www.the-game.com

16. http://www.starwars.com

17. http://www.citysearch.com

18. http://www.fox.searchlight.com

(The Full Monty - Movie)

\section{Food}

19. http://www.certs.com

20. http://www.drpepper.com

21. http://www.sonic.com

22. http://www.m-ms.com (m\&m's candies)

23. http://www.tyson.com (Tyson Chicken)

24. http://www.millerlite.com

25. http://www.pepsi.com/peacemaker

26. http://www.ironkids.com (Bread)

27. http://www.sonicdrivein.com

\section{Home}

28. http://www.roomstore.com

29. http://www.clothesline.com (Tide Detergent)

30. http://www.clothes.com (Tide Detergent)

31. http://www.minwax.com
32. http://www.lazboy.com (La-Z-Boy Chairs)

33. http://www.sears.com

34. http://www.whirlpool.com

35. http://www.bestbuy.com

36. http://www.serta.com

37. http://www.kodak.com

38. http://www.maytag.com

39. http://www.pier1.com

\section{Personal}

40. http://www.levi.com

41. http://www.menswearhouse.com

\section{Pleasure}

42. http://www.nintendo.com

\section{Healthcare}

43. http://www.clearasil.com

44. http://www.claritin.com

45. http://www.tampax.com

46. http://www.alpha-hydrox.com

(Alpha Hydroxy Skin Care)

47. http://www.nicorette.com

48. http://www.monistat.com

49. http://www.mentadent.com

50. http://www.ahhh-alegra.com

\section{Business}

51. http://www.visa.com

52. http://www.sprint.com

53. http://www.swbell.com

54. http://www.goarmy.com (U.S. Army)

55. http://www.beaconeye.com

(Laser PRK surgery)

56. http://www.sprint.com/onedime

57. http://www.metlife.com

58. http://www.mastercard.com

59. http://www.thenewsteel.com

60. http://www.ibm.com 
Exhibit 2

\section{Direct Response Channel Location on Television Screen}

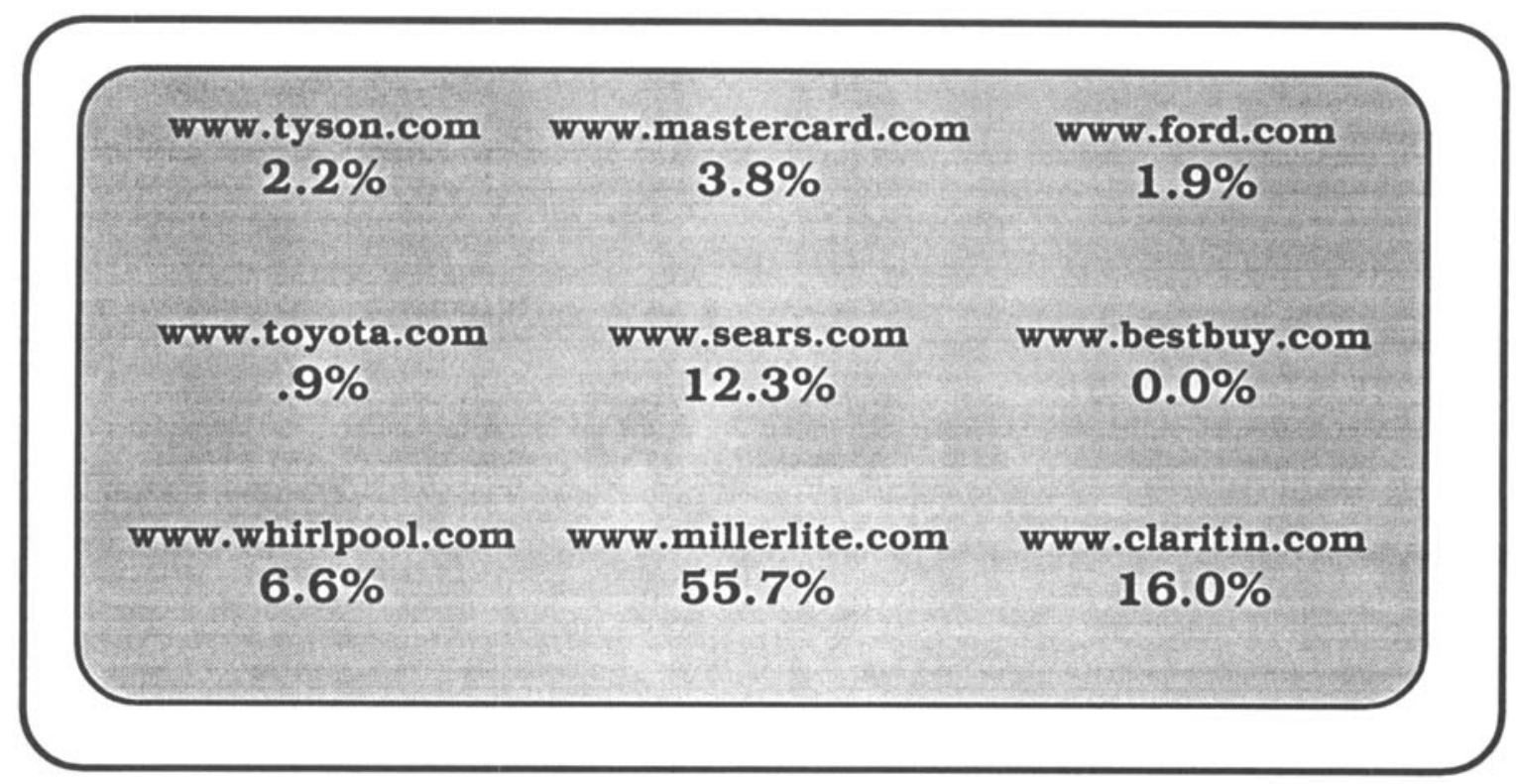

*URLs are for illustrative purposes only.

Exhibit 3

Example of Direct Response Message Sizes in Television Advertisements

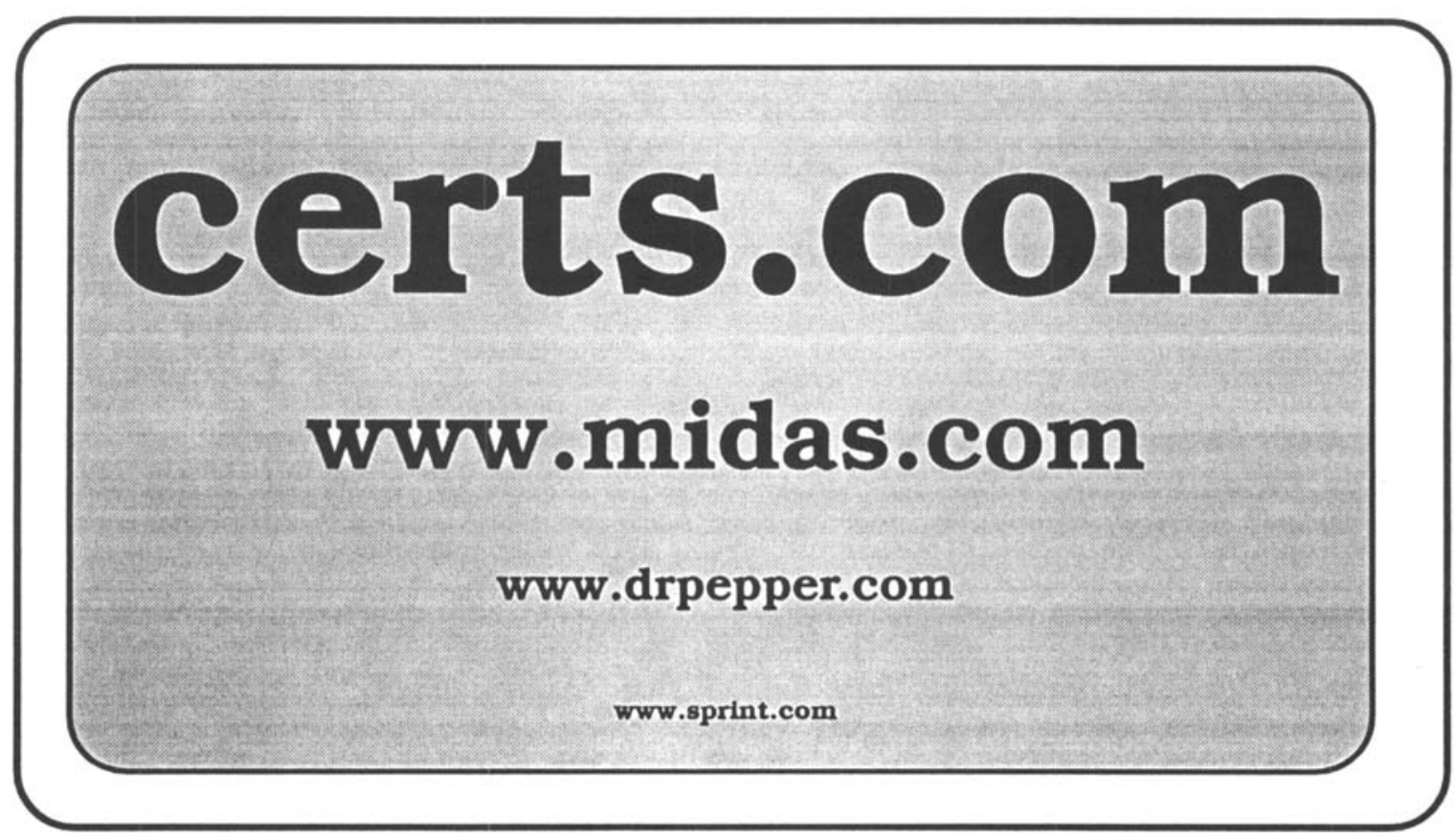

URLs to scale of screen. Size shown is the largest value of each range.

www.certs.com $=10.1 \%$ to $20 \%$ www.drpepper.com $=$

www.midas.com $=5.1 \%$ to $10 \%$ www.drpepper.com $=$

$2.0 \%$ to $5 \%$


Table 1

Summary of Direct Response Channel Findings-Without Duplication

$(\mathrm{N}=106)$

\begin{tabular}{|c|c|c|c|c|c|c|c|c|}
\hline \multirow[t]{2}{*}{ Type of DRC } & \multicolumn{2}{|c|}{$\begin{array}{c}U R L \\
n=69\end{array}$} & \multicolumn{2}{|c|}{$\begin{array}{c}800 \text { Number } \\
n=27\end{array}$} & \multicolumn{2}{|c|}{$\begin{array}{l}\text { Local Number } \\
\qquad n=10\end{array}$} & \multicolumn{2}{|c|}{$\underset{n=106}{\text { Total }}$} \\
\hline & $n$ & Percent & $n$ & Percent & $n$ & Percent & $n$ & Percent \\
\hline \multicolumn{9}{|l|}{ Verbal Reference } \\
\hline $\begin{array}{l}\text { Yes } \\
\text { No }\end{array}$ & $\begin{array}{r}7 \\
62\end{array}$ & $\begin{array}{l}10.1 \% \\
89.9 \%\end{array}$ & $\begin{array}{r}8 \\
19\end{array}$ & $\begin{array}{l}29.6 \% \\
70.4 \%\end{array}$ & $\begin{array}{l}5 \\
5\end{array}$ & $\begin{array}{l}50.0 \% \\
50.0 \%\end{array}$ & $\begin{array}{l}20 \\
80\end{array}$ & $\begin{array}{l}18.9 \% \\
81.1 \%\end{array}$ \\
\hline \multicolumn{9}{|l|}{ Reason Given } \\
\hline $\begin{array}{l}\text { None } \\
\text { Information } \\
\text { To Order }\end{array}$ & $\begin{array}{r}63 \\
4 \\
2\end{array}$ & $\begin{array}{r}91.3 \% \\
5.8 \% \\
2.9 \%\end{array}$ & $\begin{array}{r}20 \\
3 \\
4\end{array}$ & $\begin{array}{l}74.1 \% \\
11.1 \% \\
14.8 \%\end{array}$ & $\begin{array}{l}7 \\
1 \\
2\end{array}$ & $\begin{array}{l}70.0 \% \\
10.0 \% \\
20.0 \%\end{array}$ & $\begin{array}{r}90 \\
8 \\
8\end{array}$ & $\begin{array}{r}85.0 \% \\
7.5 \% \\
7.5 \%\end{array}$ \\
\hline \multicolumn{9}{|l|}{ When Presented } \\
\hline $\begin{array}{l}\text { Beginning } \\
\text { Middle } \\
\text { End }\end{array}$ & $\begin{array}{r}2 \\
1 \\
66\end{array}$ & $\begin{array}{r}2.9 \% \\
1.4 \% \\
95.7 \%\end{array}$ & $\begin{array}{r}3 \\
1 \\
23\end{array}$ & $\begin{array}{r}11.1 \% \\
3.7 \% \\
85.2 \%\end{array}$ & $\begin{array}{l}2 \\
1 \\
7\end{array}$ & $\begin{array}{l}20.0 \% \\
10.0 \% \\
70.0 \%\end{array}$ & $\begin{array}{r}7 \\
3 \\
96\end{array}$ & $\begin{array}{r}6.6 \% \\
2.8 \% \\
90.6 \%\end{array}$ \\
\hline \multicolumn{9}{|l|}{ Where on Screen } \\
\hline $\begin{array}{l}\text { Top/Left } \\
\text { Top/Center } \\
\text { Top/Right } \\
\text { Middle/Left } \\
\text { Middle/Center } \\
\text { Middle/Right } \\
\text { Bottom/Left } \\
\text { Bottom/Center } \\
\text { Bottom/Right }\end{array}$ & $\begin{array}{r}3 \\
2 \\
2 \\
0 \\
4 \\
0 \\
7 \\
39 \\
12\end{array}$ & $\begin{array}{r}4.3 \% \\
2.9 \% \\
2.9 \% \\
0.0 \% \\
5.8 \% \\
0.0 \% \\
10.1 \% \\
56.5 \% \\
17.4 \%\end{array}$ & $\begin{array}{r}0 \\
2 \\
0 \\
1 \\
6 \\
0 \\
0 \\
14 \\
4\end{array}$ & $\begin{array}{r}0.0 \% \\
7.4 \% \\
0.0 \% \\
3.7 \% \\
22.1 \% \\
0.0 \% \\
0.0 \% \\
51.9 \% \\
14.8 \%\end{array}$ & $\begin{array}{l}0 \\
0 \\
0 \\
0 \\
3 \\
0 \\
0 \\
6 \\
1\end{array}$ & $\begin{array}{r}0.0 \% \\
0.0 \% \\
0.0 \% \\
0.0 \% \\
30.0 \% \\
0.0 \% \\
0.0 \% \\
60.0 \% \\
10.0 \%\end{array}$ & $\begin{array}{r}3 \\
4 \\
2 \\
1 \\
13 \\
0 \\
7 \\
59 \\
17\end{array}$ & $\begin{array}{r}2.2 \% \\
3.8 \% \\
1.9 \% \\
.9 \% \\
12.3 \% \\
0.0 \% \\
6.6 \% \\
55.7 \% \\
16.0 \%\end{array}$ \\
\hline \multicolumn{9}{|l|}{ Size of DRC } \\
\hline $\begin{array}{l}<2 \% \\
2 \%-5 \% \\
5.1 \%-10 \% \\
10.1 \%-20 \%\end{array}$ & $\begin{array}{r}21 \\
35 \\
11 \\
2\end{array}$ & $\begin{array}{r}30.4 \% \\
50.7 \% \\
15.9 \% \\
2.9 \%\end{array}$ & $\begin{array}{r}2 \\
11 \\
8 \\
6\end{array}$ & $\begin{array}{r}7.4 \% \\
40.7 \% \\
29.6 \% \\
22.2 \%\end{array}$ & $\begin{array}{l}0 \\
1 \\
5 \\
4\end{array}$ & $\begin{array}{r}0.0 \% \\
10.0 \% \\
50.0 \% \\
40.0 \%\end{array}$ & $\begin{array}{l}23 \\
47 \\
24 \\
12\end{array}$ & $\begin{array}{l}21.7 \% \\
44.3 \% \\
22.6 \% \\
11.3 \%\end{array}$ \\
\hline \multicolumn{9}{|l|}{ Frequency of DRC } \\
\hline $\begin{array}{l}\text { Once } \\
\text { Twice } \\
\text { Three Times } \\
\text { Constant }\end{array}$ & $\begin{array}{r}68 \\
1 \\
0 \\
0\end{array}$ & $\begin{array}{r}98.6 \% \\
1.4 \% \\
0.0 \% \\
0.0 \%\end{array}$ & $\begin{array}{r}23 \\
1 \\
3 \\
0\end{array}$ & $\begin{array}{r}85.2 \% \\
3.7 \% \\
11.1 \% \\
0.0 \%\end{array}$ & $\begin{array}{l}7 \\
0 \\
2 \\
1\end{array}$ & $\begin{array}{r}70.0 \% \\
0.0 \% \\
20.0 \% \\
10.0 \%\end{array}$ & $\begin{array}{r}98 \\
2 \\
5 \\
1\end{array}$ & $\begin{array}{r}92.5 \% \\
1.9 \% \\
4.7 \% \\
.9 \%\end{array}$ \\
\hline
\end{tabular}


sumers. The study provides a bench mark against which the growth and style of direct response advertising of the internet in mass media can be judged in the future. Presently, of the unique television commercials sampled, $20.6 \%$ provided a web address on screen. It is expected that this number will grow in the future as more companies go on-line and internet penetration increases among consumers. Other results focused on the structural components of URLs, presenting a picture of the product categories, positioning (where/when), size, frequency, and length of the commercials in which URLs were presented. The following briefly summarizes these results: Automobile ads presented the most URLs; URLs were most commonly shown at the end of ads, in the bottom center part of the screen; and just over half of the URLs were between 2 and $5 \%$ of screen size, with the vast majority only being presented once during a commercial.

Each of the URL findings was compared with the other DRCs. URLs were found to be the most widely used response format $(65.1 \%)$, eclipsing even 800 numbers $(\mathbf{2 5 . 5 \%})$ as the direct response channel of choice. Almost uniformly, advertisers presented their DRC references at the end of the ad (90.6\% overall). This placement goes against the notion that information presented early has a better chance of gaining attention. However, one could also argue placement at the end is logical, because if an ad is considered interesting by the viewer; by the end of the commercial, the consumer should be motivated to respond. Unfortunately, many of the DRC references were presented for only a very short time, thereby making them difficult to process wherever they appeared.

Regarding the physical location of the DRC on the screen, they were most commonly found at the bottom of the screen in the center $(55.7 \%)$, however DRCs could be found at almost any location on the screen. Placement of DRC references deserve careful attention and planning, as the camera should lead viewers into it. Most likely the current placement of URLs are an after thought, however there were several creative uses ofDRCs that incorporated phone numbers into the ads. Ads for 800 Collect had the number on items in the commercials, such as a bus stop bench, or a chalk board in a classroom, that made the DRC central to the theme of the ad.

Again this was the exception and not the rule. In fact, the DRCs of some advertisers are so small, you would think they were trying to hide them from the viewer as if they were disclosure statements. The most common size for a DRC was between 2 and $5 \%$ of the screen, which is easily readable; but $21.7 \%$ of the DRCs were less than $2 \%$ of the screen, making them very hard to read even up close. With respect to frequency, most advertisers presented their contact information only once $(92.5 \%)$ and few verbally directed consumers toward web sites. A bright spot was again the 800 Collect ads featuring their 800 number multiple times and some even provided a reason for consumers to use the service. Perhaps advertisers should follow the wisdom of more established direct response channels (e.g. 800 numbers) when attempting to develop effective structural characteristics of URLs.

Past research has already indicated a low correlation between URLs seen in television ads and visits to referenced web sites (Maddox, Mehta and Daubek 1997). Of course part of the problem resides in the limited access and low penetration of the internet, however advertisers must also accept some of the responsibility. The findings of this study illustrate that URLs presented in cross media promotions offer little chance of being noticed beyond their novelty, as the URLs are too small, and in some cases unreadable. Also, they do not convey a call to action on the part of the consumer, and no information is provided as to what the consumer can expect to find if they do visit a company's web site.

\section{Revisiting the Bullet Theory}

Similar to the advertisers of the early twentieth century, advertisements that present web addresses in the mass media appear to have a "bullet theory" mentality. Schramm (1974) stated that advertisers of the past viewed communication, "as a magic bullet that transfers ideas or feelings or knowledge or motivations almost automatically from one mind to another," (p. 8). But the bullet theory lost favor, because it did not adequately explain the actions of consumers. As Schramm (1974) went on to say, "The audience, when hit by the bullet [the message] refused to fall over," (p.9). This is a lesson that should be remembered by advertisers presently using mass media to promote their web sites. Today, URLs appear to be simply tacked on to existing ads and placed in the mass media with the expectation that consumers will "be hit" and respond. The presentation of URLs appear to have been given little thought in terms of traditional advertising wisdom such as font sizes large enough to read, placement considerations, and frequency. And even if URLs do get noticed, research by Maddox, Mehta and Daubek (1997) indicates that few people are actually visiting the web sites referenced.

Although advertisers may presently be counting on the high interest level in the internet itself to lure customers to web sites, consumers must be offered 
something self-relevant to be motivated into action. Unlike traditional advertising goals of exposure or liking, URLs encourage immediate action and must therefore promise the consumer a benefit for seeking out the web site. Unfortunately, many advertisers seem to be ignoring this fundamental exchange, hoping instead that the mere fact that a company has built a web site means that consumers will visit. But, as the presence of URL references increase, they may start to go un-noticed, lowering their ability to elicit consumer attention.

Of course, it could be argued that advertisers' motives for presenting URLs in television commercials have nothing to do with driving consumers to web sites. Perhaps, all advertisers are hoping for is to gain the attention of the audience through a novelty effect of seeing or hearing web addresses. Or perhaps many companies are just jumping on the band wagon, flashing URLs to look modern with the goal of creating positive consumer affect. However, in either situation wear out will eventually occur leaving advertisers in need of another gimmick, while still faced with the task of bringing consumers to their web sites.

One method of bringing consumers to web sites is through the use of cross media promotion, however care must be taken to ensure that it is implemented effectively. Currently, it seems as if cross media promotion is an after thought, giving little regard to structural factors in presenting the URLs or message content of why consumers should care.

Although the internet provides an ideal channel for building bonds with consumers in a two-way exchange of information, the task is complex because consumers have control of the relationship. Consumers direct themselves to information about products and/or services that they find personally relevant. With the customer at the helm, an advertiser's first goal must focus on attracting attention and enticing consumers to seek out a company's web site.

In order to implement successful relationship building using the internet, advertisers need to change their thinking about the purpose of mass media advertising. Presently, URLs in television commercials are too small to process and consumers are not being provided with any reason to visit the web sites promoted. While advertisers are quite skilled at presenting their products in the best possible light (size, shape, color etc.) and clearly emphasize the attributes of their products, they also need to advertise the qualities and attributes of their web sites. Web sites need to be thought of as products requiring their own strategies and executions for gaining attention, increasing awareness, likability, and trial if companies wish to attract consumers, communicate effectively, and engage in lasting relationships.

\section{References}

Alba, Joseph W. and J. Wesley Hutchinson (1988), "Dimensions of Consumer Expertise," Joumal of Consumer Research, 13 (March), 411-454.

Anonymous (1995), "1-800-get-1-now," American Demographics, (June), 34.

Bezjian-Avery, Alexa, Bobby Calder and Dawn Iacobucci (1998), "New Media Interactive Advertising vs. Traditional Advertising," Journal of Advertising Research, 38(July/ August), 23-32.

Bloch, Peter H., Daniel L. Sherrell and Nancy M. Ridgway (1986), "Consumer Search: An Extended Framework," Journal of Consumer Research, 13(June), 119-126.

Briggs, Rex and Nigel Hollis (1997), "Advertising on the Web: Is there Response before Click-Through?" Journal of Advertising Research, 37(March/April), 33-46.

Brucks, Merrie (1985), “The Effects of Product Class Knowledge on Information Search Behavior," Journal of Consumer Research, 12(June), 1-16.

Buck, Rinker (1993), "Marketing's Latest 'Magic Bullet'," Brandweek, $34(23), 12$.

Cobb, Cathy J. and Wayne D. Hoyer (1985), "The Influence of Advertising at the Moment of Brand Choice," Journal of Advertising, 14 (Winter), 5-12.

Coffey, Steve and Horst Stipp (1997), "The Interactions between Computer and Television Usage," Journal of Advertising Research, 37(March/A pril), 61-67.

CommerceNet (1997), "The Commerce Net/Nielson Internet Demographics Survey: Spring '97 release. Available: [http:// www.commerce.net/work/pilot/nielson_96/].

Cook, William A. (1994), "Is It Interactive Media, or Hyperactive Media?" Jounzal of Adiertising Research, 34(January/February), 7-9.

Direct Marketing (1987), "Behavior and Attitudes of Telephone Shoppers," 50(October), 66-71.

Dreze, Xavier and Fred Zurfryden (1997), "Testing Web Site Design and Promotional Content," Journal of Advertising Research, 37(March/ April), 77-91.

- and (1998), "Is Internet Advertising Ready for Primetime?" Journal of Advertising Research, 38 (May/ June), 7-18.

estats (1999), Accessed May 19, 1999: [http:/ / www.e-land.com].

Foxman, Ellen R., Darrel D. Muehling and Patrick A. Moore (1988), "Disclaimer Footnotes in Ads: Discrepancies Between Purpose and Performance," Journal of Public Policy and Marketing, 7, 127-137.

Ghose, Sanjoy and Wenyu Dou (1998), "Interactive Functions and Their Impacts on the Appeal of Internet Presence Sites," Jourual of Advertising Research, 38(January/February), 29-43.

Girish, N. Punj and Richard Staelin (1983), "A Model of Consumer Search Behavior for New Automobiles," Journal of Consumer Research, 9 (March), 366-380.

Griffin, Ken, Roy Whitehead and Rebecca Gatlin (1998), "Banner Advertising on the World Wide Web: An Analysis," International Joumal of Management, 15(June), 262-265.

Hillson, James (1995), on "Goodbye Guess Work," Video of the Advertising Education Foundation, Dick Young Productions, Ltd., New York City.

Hoffman, Donna L., Thomas P. Novak and Patrali Chatterjee, (1995), "Commercial Scenarios for the Web: Opportunities and Challenges," Journal of Computer-Mediated Communication, 1(3), [URL:http://shum.huji.ac.il/jcmc/vol1/issue3/vol1no3.htm]]. , W.D. Kalsbeek and Thomas P. Novak (1996), "Internet Use In The United States: 1995 Baseline Estimates and Preliminary Market Segments. Available: [http://www2000.ogsm.vanderbilt. edu/baseline/1995.internet.estimates.html]. 
Hoy, Mariea Grubbs and Michael J. Stankey (1993), "Structural Characteristics of Televised Advertising Disclosures: A Comparison With the FTC Clear and Conspicuous Standard," Journal of Advertising, 22(June), 47-58.

Internet Advertising Bureau (1999), Accessed May 19, 1999 [http:/ /www.iab.net].

Jupiter Communications (1999), [URL: http:/ / www.webtrack.com].

Kiel, Geoffrey C. and Roger A. Layton (1991), "Dimensions of Consumer Information Seeking Behavior," Journal of Marketing Research, 28 (May), 233-239.

Leckenby, John D. and Jong-Pil Hong (1998), “Using Reach/Frequency for Web Media Planning," Journal of Advertising Research, (January/February), 7-20.

Lewis, Herschell G. (1989), "An Irreverent Look at 800 Numbers," Direct Marketing, 52 (August), 26-29.

Maddox, Lynda M., Darshan Mehta and Hugh G. Daubek (1997), "The Role and Effect of Web Addresses in Advertising," Journal of Advertising Research, 37(March/April), 47-60.

McKenna, Regis (1995), "Real-Time Marketing," Harvard Business Review, July, 87-95.

MRI Cyber Stats (1999), Accessed May 19, 1999 [http:// mediamark.com].

Muehling, Darrel D. and Richard H. Kolbe (1997), "Fine Print in Television Advertising: Views From the Top," Journal of Advertising, 26(Fall), 1-14.

(1998), "A Comparison of Children's and Prime-Time Fine-Print Advertising Disclosures Practices," Journal of Advertising, 27(Fall), 37-48.

Peppers, Don and Martha Rogers (1993), The One To One Future, New York: Currency/Doubleday. (1997), Enterprise One To One: Tools For Competing in the Interactive Age, New York: Currency/Doubleday.

Prabu, David (1998), "News Concreteness and Visual-Verbal Association: So News Pictures Narrow the Recall Gap Between Concrete and Abstract News?" Human Communication Research, 25 (2), 180-201.

Raman, Niranjan V. (1996), "Determinants of Desired Exposure to Interactive Advertising," Dissertation, The University of Texas at Austin.

Sanghavi, Nitin (1987), "Harrods Reaches Out With Its Plush Touch," Direct Marketing, 49(April), 43-47.
Schramm, William (1974), "The Nature of Communication between Humans," in D. Roberts and W. Schramm, (eds.) The Process and effects of Mass Communication, 2nd Edition, 3-53.

Shaddick, Colin (1998), "Internet Advertising Poised to Change Buyer's Habits," Marketing Week, 20(January 15), 32-33.

Smith, Robert E. (1993), "Integrating Information from Advertising and Trial: Process and Effects on Consumer Response to Product Information," Joumal of Marketing Reseanch, 30 (May), 204-219.

Spooner, John (1997), "PointCast to offer pay-per-click pricing program," Mediazweek, July 21, 20.

Stigler, George J. (1961), "The Economics of Information," Journal of Political Economy, 69 (June), 213-225.

Taylor, Charles and Barbara Stern (1997), "Asian-Americans: Television Advertising and the 'Model Minority' Stereotype," Journal of Advertising, 26 (Summer), 47-61.

Unnava, H. Rao and Robert E. Burnkrant (1991), "An ImageryProcessing View of the Role of Pictures in Print Advertising," Journal of Marketing Research, 28 (May), 226-231.

and Sunil Erevelles (1994), "Effects of Presentation Order and Communication Modality on Recall and Attitude," Journal of Consumer Research, 21 (December), 481-490.

Wendland, Mike (1998), "Internet Viewing Impacts TV Viewing in Big Way," Observer-Eccentric Newspaper Chain, (November 8), Accessed May 20, 1999 [http://www. pcmike.com/special reports/netandTVhtml.htm].

Wood, Leslie (1998), "Internet Ad Buys-What Reach and Frequency Do They Deliver?" Journal of Advertising Research, 38Uanuary/ February), 21-28.

Woodside, Arch G. (1994), "Modeling Linkage-Advertising: Going Beyond Better Media Comparisons," Journal of Advertising Research, 34(July/August), 22-31.

Yarbrough, John F. (1996), "Putting the Pieces Together," Sales and Marketing Management, 148, (9), 68-77.

\section{Endnote}

'Due to technical difficulty, taping of Wednesday \& Thursday had to be substituted with the following week. 